\title{
The Goddard multi-scale modeling system with unified physics
}

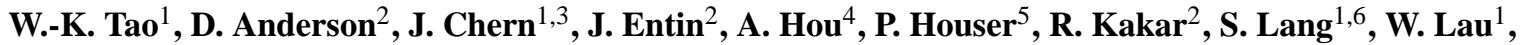 \\ C. Peters-Lidard ${ }^{7}$, X. Li ${ }^{1,3}$, T. Matsui ${ }^{1,3}$, M. Rienecker ${ }^{4}$, M. R. Schoeberl ${ }^{8}$, B.-W. Shen ${ }^{1,9}$, J. J. Shi ${ }^{1,3}$, and X. Zeng ${ }^{1,3}$ \\ ${ }^{1}$ Laboratory for Atmospheres, NASA/Goddard Space Flight Center, Greenbelt, MD, USA \\ ${ }^{2}$ NASA Headquarters, Washington, D.C., USA \\ ${ }^{3}$ Goddard Earth Sciences and Technology Center, University of Maryland at Baltimore County, Baltimore, MD, USA \\ ${ }^{4}$ Goddard Modeling Assimilation Office NASA/Goddard Space Flight Center, Greenbelt, MD, USA \\ ${ }^{5}$ George Mason University \& Center for Research on Environment and Water, Calverton, MD, USA \\ ${ }^{6}$ Science Systems and Applications Inc., Greenbelt, MD, USA \\ ${ }^{7}$ Laboratory for Hydrospheric Processes, NASA/Goddard Space Flight Center, Greenbelt, MD, USA \\ ${ }^{8}$ Earth Science Directorate, NASA/Goddard Space Flight Center, Greenbelt, MD, USA \\ ${ }^{9}$ Earth System Science Interdisciplinary Center, University of Maryland at College Park, College Park, MD, USA
}

Received: 6 January 2009 - Revised: 7 July 2009 - Accepted: 17 July 2009 - Published: 6 August 2009

\begin{abstract}
Recently, a multi-scale modeling system with unified physics was developed at NASA Goddard. It consists of (1) a cloud-resolving model (CRM), (2) a regional-scale model, the NASA unified Weather Research and Forecasting Model (WRF), and (3) a coupled CRM-GCM (general circulation model, known as the Goddard Multi-scale Modeling Framework or MMF). The same cloud-microphysical processes, long- and short-wave radiative transfer and landsurface processes are applied in all of the models to study explicit cloud-radiation and cloud-surface interactive processes in this multi-scale modeling system. This modeling system has been coupled with a multi-satellite simulator for comparison and validation with NASA high-resolution satellite data.

This paper reviews the development and presents some applications of the multi-scale modeling system, including results from using the multi-scale modeling system to study the interactions between clouds, precipitation, and aerosols. In addition, use of the multi-satellite simulator to identify the strengths and weaknesses of the model-simulated precipitation processes will be discussed as well as future model developments and applications.
\end{abstract}

Keywords. Atmospheric composition and structure (Aerosols and particles; Cloud physics and chemistry) Meteorology and atmospheric dynamics (Precipitation)

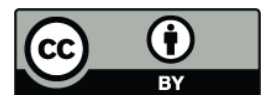

Correspondence to: $\mathrm{W} . \mathrm{K}$. Tao (wei-kuo.tao-1@nasa.gov)

\section{Introduction}

The foremost challenge in parameterizing subgrid convective clouds and cloud systems in large-scale models is the many coupled, physical processes (i.e., radiation and surface processes) that interact over a wide range of scales, from microphysical scales to the meso-scale. This makes the comprehension and representation of convective clouds and cloud systems one of the most complex scientific problems in earth science. On one hand, clouds and cloud systems owe their origin to large-scale dynamic and thermodynamic forcing, radiative cooling in the atmosphere, and turbulent transfer processes at the surface (e.g., the transfer of heat and moisture from the ocean to the atmosphere). On the other hand, clouds and cloud systems serve as important mechanisms for the vertical redistribution of momentum, trace gases (including the greenhouse gas, $\mathrm{CO}_{2}$ ), aerosols, and sensible and latent heat on the large-scale. It is also generally accepted that the proper representation of physical cloud processes in GCMs (general circulation models) is vital to advancing their predictive skill of the water and energy cycles.

As such, the highest science priority identified in the Global Change Research Program (GCRP) is the role of clouds and their interaction with radiation in climate and hydrological systems. For this reason, the Global Energy and Water Cycle Experiment (GEWEX) formed the GEWEX Cloud System Study (GCSS) to address such problems. Cloud ensemble models [CEMs, also called cloudresolving models (CRMs) or cloud-system resolving models (CSRMs)] were identified as the primary means for carrying out these studies (GCSS Science Plan 1993, Moncrieff et al.,

Published by Copernicus Publications on behalf of the European Geosciences Union. 


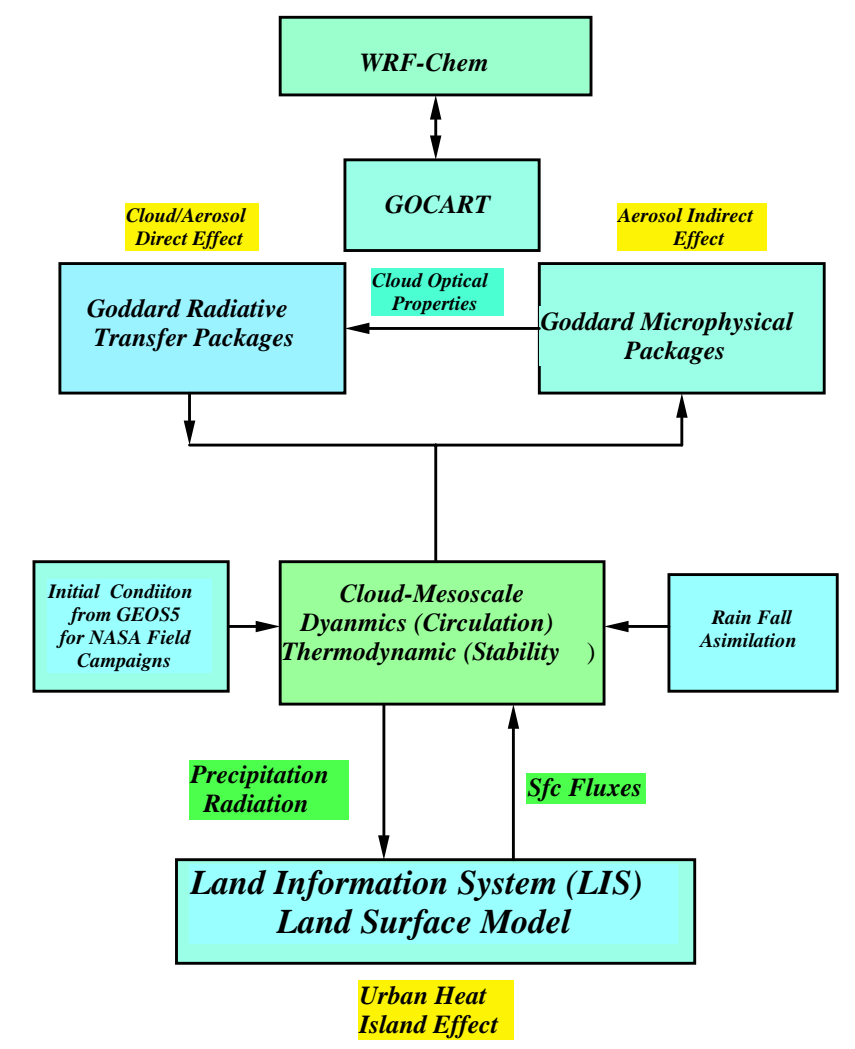

Fig. 1. Schematic diagram showing planned components of the NASA unified WRF. The blue boxes represent physical processes (packages) developed by NASA scientists. The light green boxes represent the WRF dynamical core and others (i.e., NCAR) developed outside of NASA. GOCART stands for Goddard Chemistry Aerosol Radiation and Transport model.

1997; Randall et al., 2003). CRMs now provide statistical information useful for developing more realistic statisticsor physics-based parameterizations for climate models (i.e., Norris et al., 2008).

In recent years, exponentially increasing computing power has allowed the number of computational grid points in numerical models to grow from less than a thousand to close to ten million. NWP (numerical weather prediction) and mesoscale models can now use grid resolutions similar to CRMs through nesting techniques, which in turn also allows them to use the physical packages developed and tested for CRMs.

A CRM, typically, is not a global model and can only simulate cloud ensembles over a relatively small domain (i.e., $500-1000 \times 500-1000 \mathrm{~km}^{2}$ ). To better represent convective clouds and cloud systems in large-scale models, a GCM coupled with CRMs (termed a "super-parameterization" or "multi-scale modeling framework, MMF") is required given the feasible computational power. The use of a GCM enables global coverage, while the CRMs allow for better and more sophisticated physical parameterizations (i.e., CRMbased physics). In addition, the MMF can utilize current and future satellite programs that provide cloud, precipitation, aerosol and other data at very fine spatial and temporal scales over the entire globe.

\section{The Goddard multi-scale modeling system}

\subsection{Goddard Cumulus Ensemble (GCE) model}

The GCE model, a CRM, has been developed and improved at NASA Goddard Space Flight Center over the past two and a half decades. The ability of the GCE model to simulate the impact of atmospheric aerosol concentrations on precipitation processes was recently enhanced (Tao et al., 2007) as were its abilities to account for the effects of land (Zeng et al., 2007) and ocean surface processes on convective systems in different geographic locations (Wang et al., 2003; Tao et al., 2004; Zeng et al., 2008). The GCE model's bulk microphysical scheme were recently modified to reduce the over-estimated and unrealistic amount of grauple in the stratiform region (Tao et al., 2003; Lang et al., 2007), to better address saturation issues (Tao et al., 2003) and to obtain more realistic ice water contents for longer-term simulations (Zeng et al., 2008, 2009). Recently, the GCE model has been adapted to interface with a couple of other bulk microphysical schemes, namely the single and double moment versions of the Colorado State University (CSU) Regional Atmospheric Modeling System's (RAMS's) bulk microphysical scheme (Meyers et al., 1997; Saleeby and Cotton 2004), and a spectral bin microphysical scheme (Khain et al., 2004; Tao et al., 2007; Li et al., 2009a, b). The development and main features of the GCE model were published in Tao and Simpson (1993) and Tao et al. (2003). A review on the application of the GCE model to better understand precipitation processes can be found in Tao (2003). Table 1 shows the major characteristics of the GCE model.

\subsection{Goddard unified Weather Research and Forecasting model (WRF)}

The second component of the modeling system is WRF (Michalakes et al., 2001), a next-generation mesoscale forecast model and assimilation system developed at NCAR along with several NOAA and DOD partners. The model is designed to support research advancing the understanding and prediction of mesoscale precipitation systems. It incorporates advanced numerics and data assimilation techniques and has a multiple re-locatable nesting capability as well as improved physics. WRF will be used for a wide range of applications, from idealized research to operational forecasting, with an emphasis on horizontal grid sizes in the range of $1-10 \mathrm{~km}$.

Various Goddard physical packages (i.e., CRM-based microphysics, radiation and land-surface hydrology processes) as well as a real-time forecast system using Goddard Earth Observing System (GEOS) global analyses that have been 
Table 1. Major characteristics of the Goddard Cumulus Ensemble (GCE) model.

\begin{tabular}{ll}
\hline Parameters/processes & GCE model \\
\hline Dynamics & Anelastic or compressible \\
& 2-D (slab- and axis-symmetric) and 3-D \\
Vertical coordinate & Z (height) \\
Microphysics & 2-class water \& 3-class ice \\
& 2-class water \& 2-moment 4-class ice \\
& spectral-bin microphysics \\
Numerical methods & Positive definite advection for scalar variables; \\
& 4th-order for dynamic variables \\
Initialization & Initial conditions with forcing \\
& from observations/large-scale models \\
FDDA & Nudging \\
Radiation & k-distribution and four-stream discrete-ordinate scattering (8 bands) \\
& Explicit cloud-radiation interaction \\
Sub-grid diffusion & TKE (1.5 order) \\
Surface energy budget & Force-Restore Method \\
& 7-layer soil model (PLACE) \\
& Land Information System (LIS) \\
& TOGA COARE flux module \\
Parallelization & OPEN-MP and MPI \\
\hline
\end{tabular}

developed at NASA have recently been implemented into WRF (Fig. 1). The CRM-based packages have improved forecasts (or simulations) of convective systems (e.g., a linear convective system in Oklahoma (International $\mathrm{H} 2 \mathrm{O}$ project, IHOP-2002), an Atlantic hurricane (Hurricane Katrina, 2005), high latitude snow events (Canadian CloudSat CALIPSO Validation Project, C3VP 2007), and a heavy orographic-related precipitation event in Taiwan (Summer, 2007)). In addition, two other GSFC modeling components have been coupled to the GSFC WRF representing the land surface (i.e., the Land Information System or LIS) and aerosols [i.e., the WRF Chemistry Model and Goddard Chemistry Aerosol Radiation and Transport Model (GOCART)].

\subsection{Goddard Multi-scale Modeling Framework (MMF)}

The third component of the modeling system couples the NASA Goddard finite volume GCM (fvGCM) with the GCE model (known as the Goddard MMF) ${ }^{1}$. The use of the fvGCM allows for global coverage and the use of the GCE for the explicit simulation of subgrid cloud processes and their interaction with radiation and surface processes. This

\footnotetext{
${ }^{1}$ The typical configuration for the Goddard MMF consists of the fvGCM run with $2.5^{\circ} \times 2^{\circ}$ horizontal grid spacing with 32 layers from the surface to $0.4 \mathrm{hPa}$ and the two-dimensional (2-D) GCE using 64 horizontal grids (in the east-west orientation) and 32 levels with $4 \mathrm{~km}$ horizontal grid spacing and cyclic lateral boundaries. The time step for the 2-D GCE is $10 \mathrm{~s}$, and the fvGCM-GCE coupling interval is one hour, which is the fvGCM physical time step.
}

modeling system has been applied to the study of climate scenarios such as the $1998 \mathrm{El}$ Nino and 1999 La Nina. The new coupled modeling system results in the more realistic propagation and intensity of tropical rainfall systems and intraseasonal oscillations and an improved diurnal variation of precipitation; all are difficult to capture using even state-ofthe-art GCMs with subgrid convection schemes. The new Goddard MMF is the second MMF developed worldwide following the one at CSU. Despite differences in model dynamics and physics between the Goddard and CSU MMFs, both simulate stronger MJOs, better cloudiness (high and low), single ITCZs and more realistic diurnal rainfall patterns than traditional GCMs. Both MMFs also have similar biases, such as a summer precipitation bias (relative to observations and to their parent GCMs) in Asian monsoon regions. However, there are notable differences between the two MMFs. For example, the CSU MMF simulates less rainfall over land than its parent GCM, which is why it simulates less global rainfall than its parent GCM. The Goddard MMF simulates more global rainfall than its parent GCM because of a high contribution from its oceanic component. Please see Tao et al. (2009) for a detailed discussion.

\subsection{Goddard Satellite data Simulation Unit (GSSU)}

The Goddard SDSU is a multi-satellite simulator unit. It has six simulators at present: passive microwave, radar, visible-infrared spectrum, lidar, ISCCP type, and broadband. The SDSU can compute satellite-consistent radiances or backscattering signals from simulated atmospheric profiles 


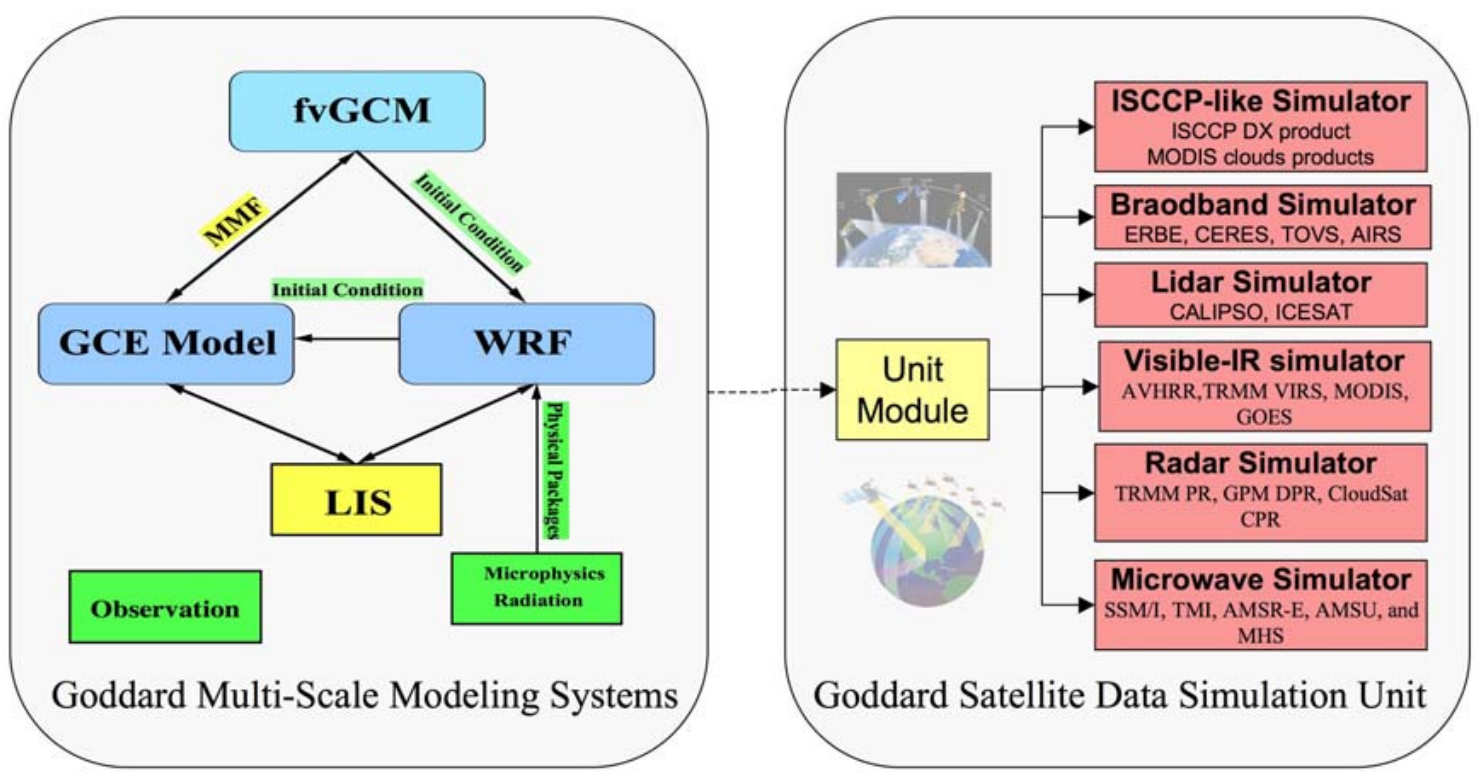

Fig. 2. Schematic diagram of the Goddard Multi-scale Modeling System with unified physics coupled with the Goddard Satellite Data Simulation Unit (SDSU). The coupling between the fvGCM and GCE is two-way [termed a multi-scale modeling framework (MMF)], while the coupling between the fvGCM and WRF and WRF and the GCE is only one-way. LIS is the Land Information System developed in the Goddard Hydrological Sciences Branch. LIS has been coupled interactively with both WRF and the GCE. Additionally, WRF has been enhanced by the addition of several of the GCE model's physical packages (i.e., microphysical scheme with four different options and short and long-wave radiative transfer processes with explicit cloud-radiation interactive processes). Observations (obtained from satellite and ground-based campaigns) play a very important role in providing data sets for model initialization and validation and consequently improvements. The Goddard SDSU can convert the simulated cloud and atmospheric quantities into radiance and backscattering signals consistent with those observed from NASA EOS satellites.

and condensates consistent with the unified microphysics within the multi-scale modeling system (Fig. 2). These simulated radiances and backscattering signatures can be directly compared with satellite observations, establishing a satellitebased framework for evaluating the cloud parameterizations. This method is superior to the traditional method of validating models with satellite-based products, since models and satellite products often use different assumptions in their cloud microphysics (Matsui et al., 2009). Once the cloud model reaches satisfactory agreement with the satellite observations, simulated clouds, precipitation, atmospheric states, and satellite-consistent radiances or backscattering will be provided to the science community as an a priori database for developing physically-based cloud and precipitation retrieval algorithms. Thus, the SDSU coupled with the multiscale modeling system can lead to a better understanding of cloud processes in the Tropics as well as improved precipitation retrievals from current and future NASA satellite missions (i.e., TRMM, the A-Train, GPM (Global Precipitation Measurement), and the ACE mission).

\section{Results}

\subsection{The importance of aerosol distributions on precipi- tation processes}

An important aspect of aerosol-cloud-precipitation interaction is the origin of the aerosols serving as cloud condensation nuclei $(\mathrm{CCN})$. The concentrations of these aerosols vary dramatically with height, depending on their source and transport. For example, urban pollution lies mainly within the boundary layer (van den Heever et al., 2006) while large dust storms are able to carry dust particles thousands of miles away with relatively high concentrations in the middle to upper troposphere (Sassen, 2002). Furthermore, local aerosols transported above the boundary layer by convection can stay aloft and sometimes be carried over long-distances. These upper-level aerosols can enter clouds through entrainment and potentially affect cloud properties.

The origins and character of model-predicted flow patterns can provide valuable insight into the mechanisms responsible for the redistribution of $\mathrm{CCN}$ and tracer constituents by deep convective systems (see review by Cotton et al., 1995; Thompson et al., 1997). Figure 3 shows the redistribution of low and midlevel tracers for two cases, a midlatitude continental squall system observed 

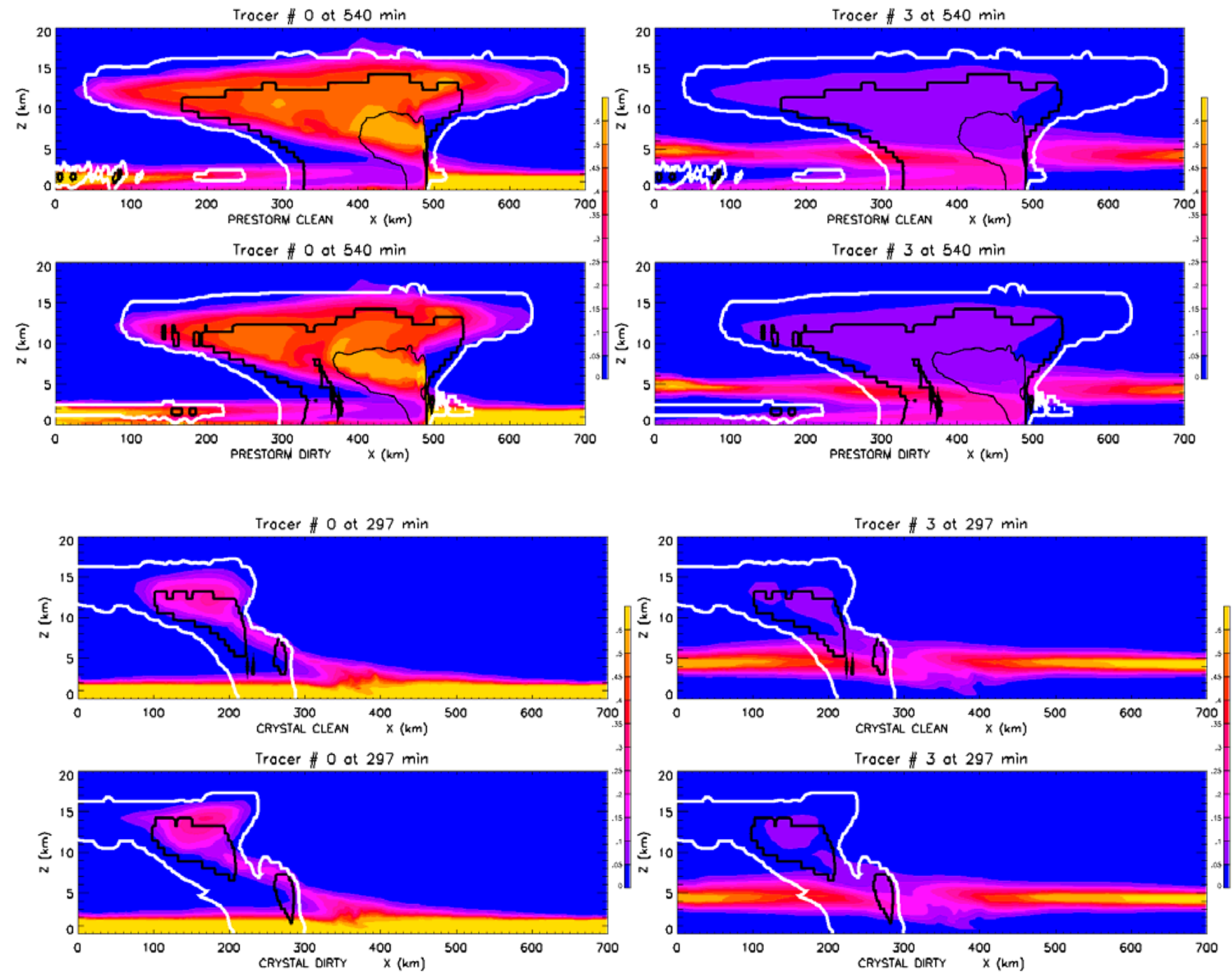

Fig. 3. Tracer analyses for a mid-latitude squall line (top four panels) and a Florida convective cloud (bottom four panels) for both clean and dirty environments. Tracers at low (from the surface to $1.5 \mathrm{~km}$, left four panels) and middle levels (from 3 to $4.5 \mathrm{~km}$, right four panels) were released to examine their respective contribution to the overlying free troposphere. The degree of vertical re-distribution is indicative of the intensity (and contribution for cloud development) of the convection and reflects the transport structure responsible for the mixing. The results show that more than $50 \%$ of the low-level tracer reaches the upper troposphere for the mid-latitude squall system compared to less than $10 \%$ for the midlevel tracer. For the Florida cloud, the low-level tracer also contributes more than 2.5 times that from mid levels.

during PRESTORM (Preliminary Regional Experiment for STORM-Central) and mid-afternoon convection observed during CRYSTAL-FACE (Cirrus Regional Study of Tropical Anvils and Cirrus Layers - Florida Area Cumulus Experiment $)^{2}$. Using tracer transport as an indicator, these simulations show that stronger, organized systems like the PRESTORM squall case are able to transport a significant amount of near surface pollutants into the upper troposphere (over 65\%). The majority of aerosols come from lower lev-

\footnotetext{
${ }^{2}$ Physical descriptions of these cases as well as their sensitivity to the initial aerosol concentrations (i.e., a clean vs. dirty environment) can be found in Tao et al. (2007).
}

els, entering into clouds via cloud base. However, a significant amount of aerosols at midlevels can be entrained through cloud sides (e.g., the CRYSTAL case). The amount of midlevel entrainment varies with storm type (i.e., updraft intensity and storm longevity). Taller cumulus with higher vertical velocities entrain more midlevel tracers than cumulus congestus. Scattered convection entrains more than organized systems (see review by Cotton et al., 1995; Levin and Cotton, 2008). Nevertheless, the ratio between lowerlevel and midlevel tracers, an indication of the importance of midlevel aerosols serving as $\mathrm{CCN}$, varies from system to system, even for the same system with different initial CCN number concentrations. 


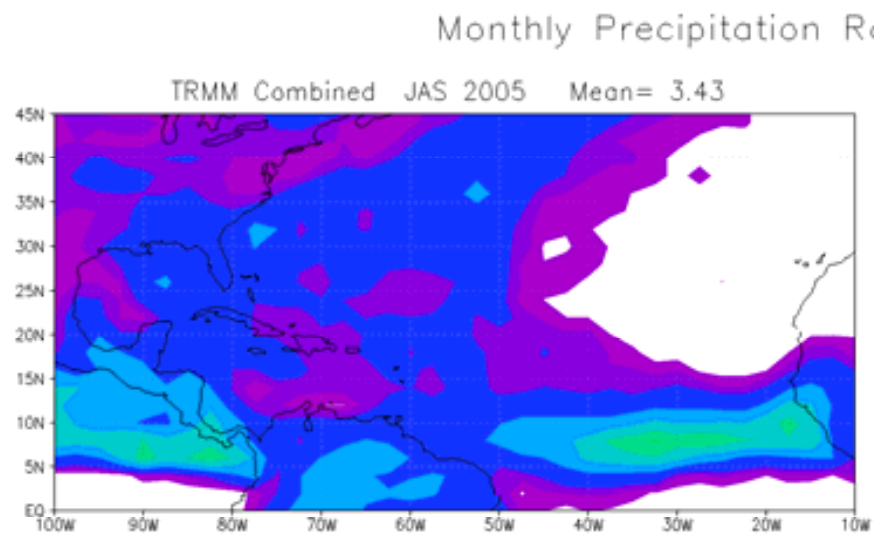

\section{Rate $(\mathrm{mm} / \mathrm{day})$}
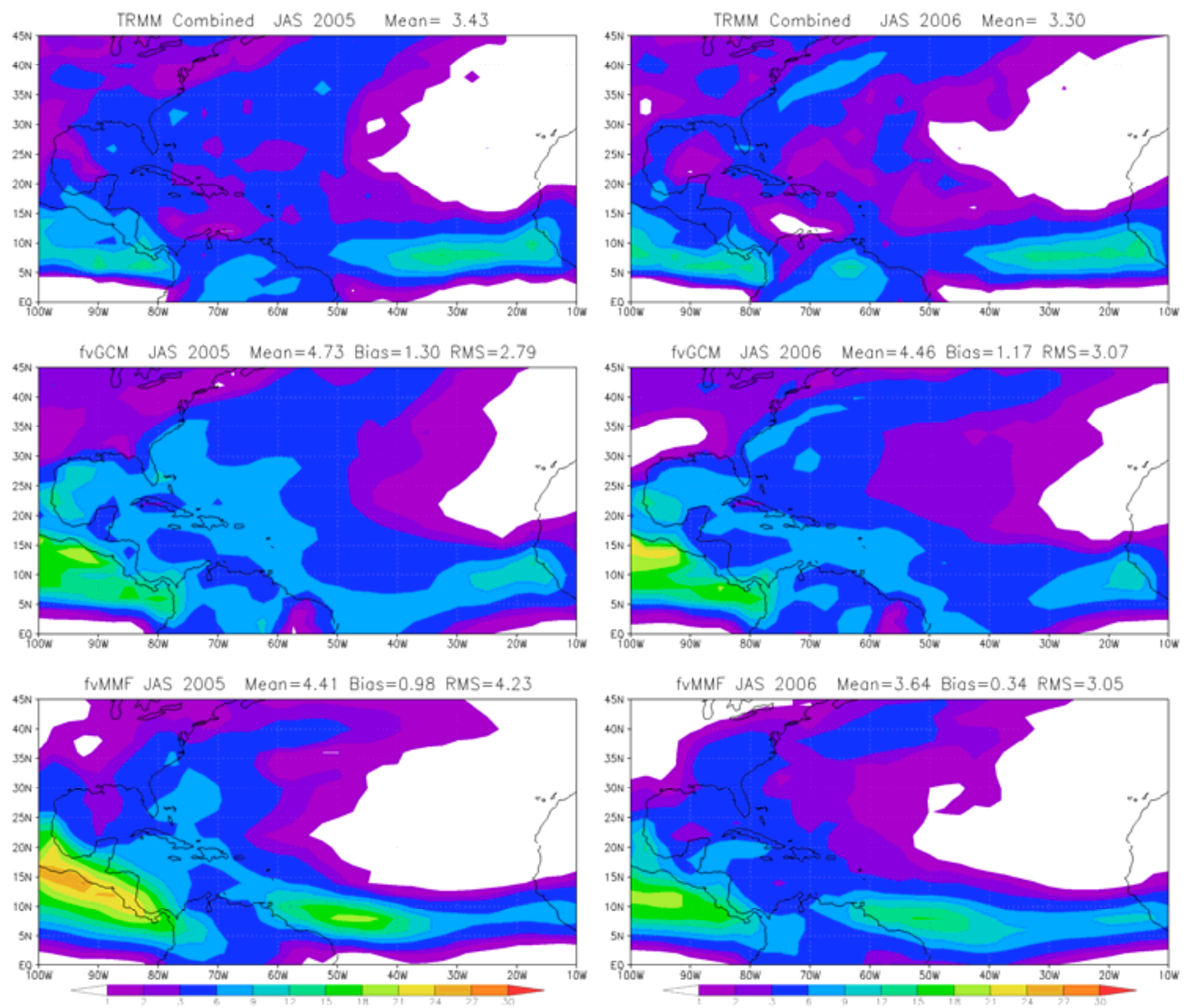

Fig. 4. Mean precipitation rates (mm/day) during the 2005 and 2006 hurricane seasons (JAS) from the TRMM combined product (upper panels), fvGCM (middle panels), and Goddard MMF (lower panels). Both models agree with the observations in simulating more precipitation during the 2005 season. The MMF has a better precipitation bias (i.e., 0.98 vs. 1.30 in 2005 and 0.34 vs. 1.17 in 2006 ) and less rainfall compared to the fvGCM. In addition, the dry areas over the subtropical Bermuda high are more realistic than in the fvGCM. However, the MMF has a higher root mean square (RMS) erro compared to the fvGCM in 2005.

\subsection{Precipitation processes during active and inactive hurricane seasons}

The 2005 Atlantic hurricane season featured a record 15 hurricanes with a record four major hurricanes (i.e., categories 3-5 on the Saffir-Simpson scale) making landfall in the US. With the ongoing tropical multi-decadal signal, record warm sea-surface temperatures (SSTs), and exceptionally low vertical wind shear over the western Atlantic and Gulf of Mexico, the near-record activity was well predicted by many forecasters. Based on similar warming trends in the Atlantic Ocean and the prevailing favorable preseason conditions, many forecasters again predicted a very active hurricane season for 2006. However, hurricane activity in the Atlantic basin was near normal with only 5 hurricanes in 2006. Lau and Kim (2007a, b) suggested that cooling of the Atlantic by Saharan dust during the early part of the season might have foiled the 2006 hurricane forecasts. On the other hand, Bell et al. (2007) suggested that El Nino might 

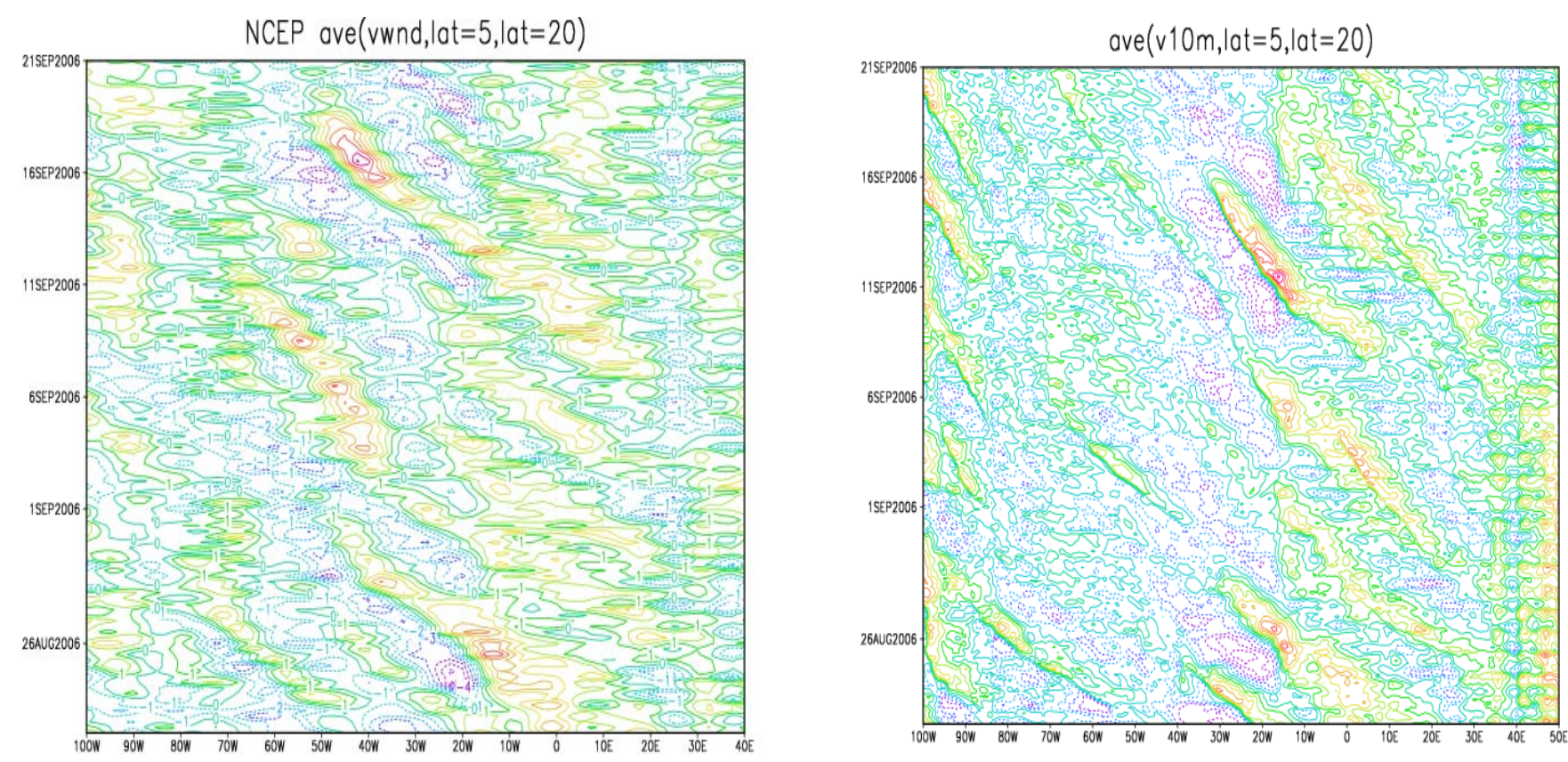

Fig. 5. Time-longitude sections of meridian winds averaged over latitudes 5-20 N from 22 August to 21 September 2006. (a) NCEP reanalysis. (b) a 30-day simulation initialized at 00:00 UTC 22 August 2006 with the high-resolution fvGCM.

have suppressed late-season (September and October) activity through anomalous upper-level convergence and sinking motion across the Caribbean Sea.

In this study, the Goddard MMF is used to study North Atlantic hurricane activity during 2005 and 2006. The model was initialized with GEOS version 4 analyses on 1 April 2005 and forced by observed NOAA OI weekly SSTs. The standard Goddard MMF at $2^{\circ}$ by $2.5^{\circ}$ horizontal resolution was used and continuously run for 3 years. The results show that the fvGCM (without CRM coupling) and Goddard MMF agree with the TRMM combined product in simulating more precipitation during the 2005 season. The MMF has a better precipitation bias with less rainfall over the North Atlantic than that of the fvGCM. In addition, the dry areas associated with the subtropical Bermuda high are more realistic than that of the fvGCM. Both models tend to produce excessive precipitation in the eastern tropical Pacific.

\subsection{Simulations of African easterly waves with the high- resolution fvGCM}

It is well known that African easterly waves (AEWs) can develop into hurricanes in the Atlantic and East Pacific. In the Atlantic, most intense hurricanes originate from AEWs. In addition, many studies (i.e., Carlson, 1969; Berry and Thorncroft, 2005) have also suggested that AEWs could modulate the features of the Inter-Tropical Discontinuity over the African continent, where the African northeasterly trade winds and southwesterly monsoon flows meet. Therefore, improving our understanding and prediction of West African rainfall and hurricane formation in the Atlantic depends on the accurate simulation of AEWs.

The high-resolution fvGCM $\left(0.25^{\circ}\right.$ by $\left.0.25^{\circ}\right)$ is used to conduct a 30-day simulation from 22 August to 21 September 2006. Figure $5 \mathrm{a}$ and $\mathrm{b}$ shows time-longitude sections of meridional winds averaged over latitudes $5 \mathrm{~N}$ to $20 \mathrm{~N}$ from NCEP reanalysis and the model simulation, respectively. In Fig. 5a, the NCEP reanalysis along longitude $20 \mathrm{~W}$ clearly shows five AEWs with an average period of 5 days. It is encouraging to see that these AEWs are simulated quite realistically as shown in Fig. 5b. However, although the formation of Tropical Storm (TS) Helene can be traced back to the 5th AEW, which passed through longitude $20 \mathrm{~W}$ on 13 September, none of the simulated AEWs developed into a hurricane over the ocean. It is hypothesized that improving the representation of moist processes and their interaction with surface fluxes might further improve the simulations of these AEWs (e.g., speed, intensity, and structure) and their interaction with the ocean, thereby improving the model's performance in simulating the formation of TS Helene. A parallel run with the MMF is being currently conducted to help verify this hypothesis.

\subsection{Evaluating model microphysics with the coupled satellite simulator}

WRF, configured with the Goddard microphysics and radiation schemes, was used to simulate two snow events (20-22 January 2007) over the C3VP site in Ontario, Canada (Shi et al., 2009). Figure 6 displays $94 \mathrm{GHz}$ radar reflectivities 

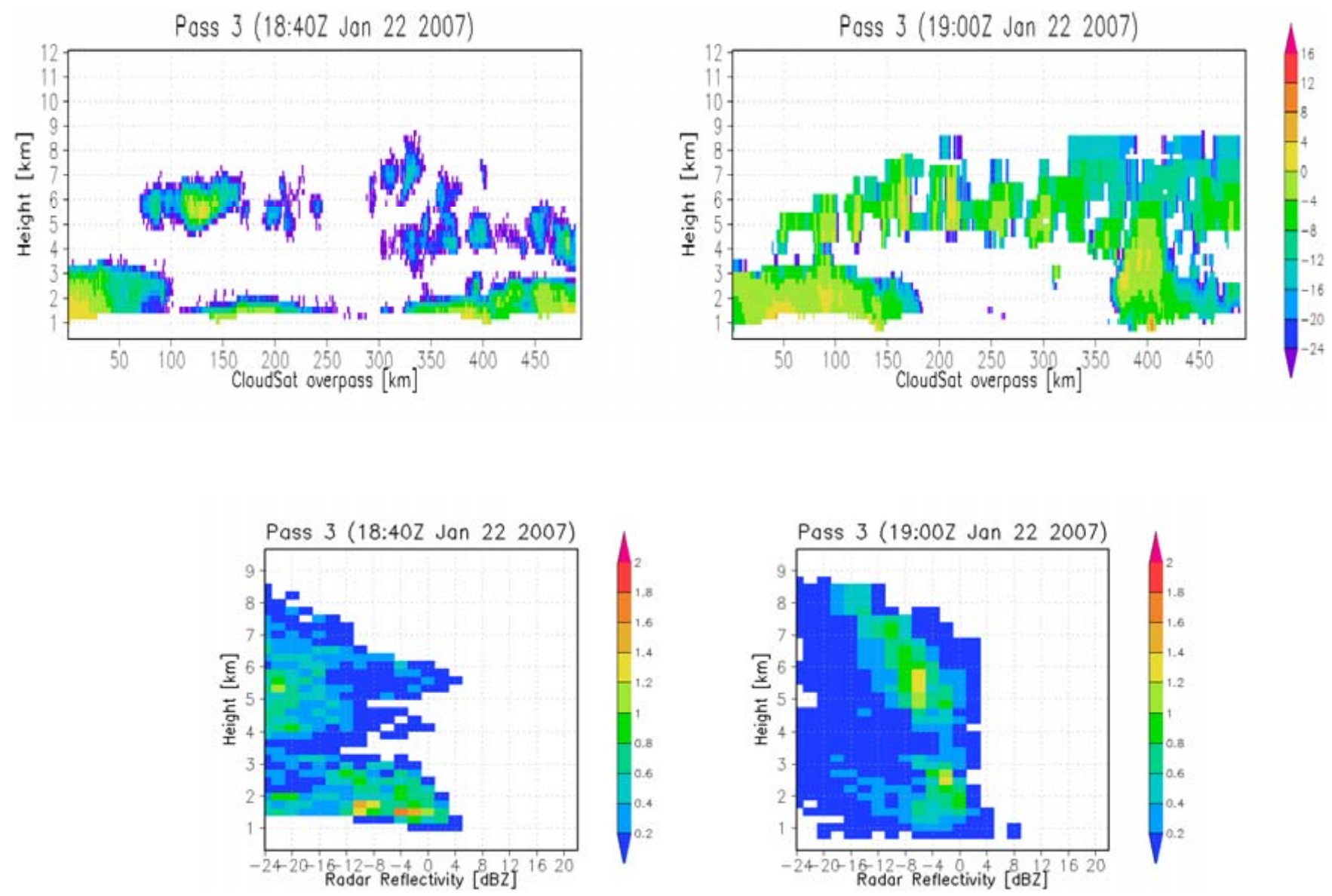

Fig. 6. (a) Instantaneous cross-sectional snap shot (upper panel) and (b) contoured frequency with altitude diagrams (CFADs) (lower panel) of CloudSAT-observed (left) and WRF-SDSU-simulated (right) Cloud Profiling Radar (CPR, 94 GHz) reflectivities.

from CloudSAT observations and WRF-SDSU simulations. The cross-sectional comparison indicates that WRF successfully captured the spatial distribution of radar reflectivity, while the statistical comparison using contoured frequency with altitude diagrams (CFADs) shows that WRF overestimated radar reflectivity above $4 \mathrm{~km}$. This result demonstrates that WRF was able to capture the cloud macro-structure reasonably well but not the cloud microphysics. An improved version of the microphysics is now being developed based largely on the comparison between model-simulated and satellite-observed cloud and precipitation properties (Matsui et al., 2009). Improved microphysics and hence model simulations are necessary to provide consistent 4-D thermodynamic and dynamic cloud data sets for future GPM snow retrievals and to improve our understanding of precipitation processes over high-latitude regions.

\section{Conclusions}

Significant advances in the use of CRMs to simulate and improve our understanding of convective dynamics and its interaction with microphysics, precipitation, clouds, radiation, surface effects and boundary layers across multiple scales have been made over the past four decades. These model simulations are vital for comprehending the interaction between cloud systems and the large-scale circulation and also play a key role in the retrieval of precipitation and latent heating from satellite measurements (i.e., Tao et al., 2006). The unified physics in the multi-scale modeling system is mainly based on those developed for the CRMs. However, the enormous dynamic range of modern CRMs presents new challenges for validation. This will involve integrated satellite simulators, satellite datasets, field-campaign analysis, CRMs, high-resolution NWP models (i.e., WRF), and the MMF.

Global CRMs have already been run on an experimental basis, made possible by ever-improving computing power (Satoh et al., 2005). It is expected that by incorporating physical packages originally developed for high-resolution process models such as CRMs into NWP models and GCMs along with the continuing development of global CRMs, the ability to simulate realistic weather and climate in the 
near future will be greatly enhanced (see Tao and Moncrieff, 2009, for more discussion).

Acknowledgements. The GCE model and WRF-GCE coupling are supported by the NASA Headquarters Atmospheric Dynamics and Thermodynamics Program and the NASA Tropical Rainfall Measuring Mission (TRMM). The Goddard MMF is supported by NASA MAP (Modeling and Analyses Prediction). The coupling between WRF-LIS and GCE-LIS is supported by the NASA Earth Science Technology Office. We also acknowledge support by the NASA Grant: NNX06AF30G - Global Environmental Changehazards and regional impacts, and support by the technical officers Don Anderson and Lucia Tsaoussi.

We also thank two anonymous reviewers for their constructive comments that improved this paper significantly.

Topical Editor F. D'Andrea thanks two anonymous referees for their help in evaluating this paper.

\section{References}

Bell, G. D., Blake, E., Landsea, C., Chelliah, M., Pasch, R., Mo, K., and Goldenberg, S.: The 2006 North Atlantic hurricane season: A climate perspective. State of the Climate in 2006, edited by: Waple, A. M. and Lawrimore, J. H., B. Am. Meteorol. Soc., 87, S1-S68, 2007.

Berry, G. J. and Thorncroft, C.: Case Study on an Intense African Easterly Wave, Mon. Weather Rev., 133, 752-766, 2005.

Carlson, T. N.: Synoptic histories of three African disturbances that developed into Atlantic hurricanes, Mon. Weather Rev., 97, 256276, 1969.

Cotton, W. R., Alexander, G. D., Hertenstein, R., Walko, R. L., McAnelly, R. L., and Nicholls, M.: Cloud Venting - A review and some new global annual estimates, Earth Sci. Rev., 39, 169206, 1995.

Browning, K. A., Betts, A., Jonas, P. R., et al.: The GEWEX Cloud System Study (GCSS), B. Am. Meteorol. Soc., 74, 387-400, 1993.

Khain, A., Pokrovsky, A., Pinsky, M., Seigert, A., and Phillips, V.: Simulation of effects of atmospheric aerosols on deep turbulent convective clouds using a spectral microphysics mixed-phase cumulus cloud model. Part I: Model description and possible applications, J. Atmos. Sci., 61, 2983-3001, 2004.

Lang, S., Tao, W.-K., Cifelli, R., Olson, W., Halverson, J., Rutledge, S., and Simpson, J.: Improving simulations of convective system from TRMM LBA: Easterly and Westerly regimes, J. Atmos. Sci., 64, 1141-1164, 2007.

Lau, K. M. and Kim, K. M.: How nature foiled the 2006 hurricane forecasts, EOS Trans. AGU, 88, 105-107, 2007a.

Lau, K. M. and Kim, K. M.: Cooling of the Atlantic by Saharan dust, Geophys. Res. Lett., 34, L23811, doi:10.1029/2007GL031538, 2007b.

Levin, Z. and Cotton, W. R. (Eds.): Aerosol Pollution Impact on Precipitation: A scientific review, Springer Press., 382 pp, 2008.

Li, X., Tao, W.-K., Khain, A., Simpson, J., and Johnson, D. E.: Sensitivity of a cloud-resolving model to bulk and explicit bin microphysical schemes. Part I: Comparisons, J. Atmos. Sci., 66, 3-21, 2009a.

Li, X., Tao, W.-K., Khain, A. P., Simpson, J., and Johnson, D. E.: Sensitivity of a cloud-resolvong model to the bulk and ex- plicit bin microphysical schemes. Part II: Cloud microphysics and storm dynamics interactions, J. Atmos. Sci., 66, 22-40, 2009b.

Matsui, T., Zeng, X., Tao, W.-K., Masunaga, H., Olson, W. S., and Lang, S.: Evaluation of long-term cloud-resolving model simulations using satellite radiance observations and multi-frequency satellite simulators, J. Atmos. Ocean. Technol., in press, 2009.

Meyers, M. P., Walko, R. L., Harrington, J. Y., and Cotton, W. R.: New RAMS cloud microphysics. Part II: The two-moment scheme, Atmos. Res., 45, 3-39, 1997.

Michalakes, J., Dudhia, J., Gill, D., Henderson, T., Klemp, J., Skamarock, W., and Wang, W.: The Weather Research and Forecast Model: Software architecture and performance. The 11th ECMWF Workshop on the Use of High Performance Computing in Meteorology, 25-29 October 2004, Reading, UK, edited by: Mozdzynski, G., 2004.

Moncrieff, M. W., Krueger, S. K., Gregory, D., Redelsperger, J.-L., and Tao, W.-K.: GEWEX Cloud System Study (GCSS) Working Group 4: Precipitating convective cloud systems, B. Am. Meteorol. Soc., 78, 831-845, 1997.

Norris, P. M., Oreopooulos, L., Hou, A., Tao, W.-K., and Zeng, X.: Clouds andcopulas: Part I: Theory for water clouds, Q. J. Roy. Meteorol. Soc., 134, 1843-1864, 2008.

Randall, D. A., Curry, J., Duynkerke, P., Krueger, S. K., Moncrieff, M. W., Ryan, B., Starr, D. O., Miller, M., Rossow, W., Tseliudis, G., and Wielikci, B. A.: Confronting models with data, The GEWEX cloud system study, B. Am. Meteorol. Soc., 84, 455469, 2003.

Saleeby S. M. and Cotton, W. R.: A large droplet mode and prognostic number concentration of cloud droplets in the Colorado State University Regional Atmospheric Modeling System (RAMS). Part I: Module descriptions and supercell test simulations, J. Appl. Meteorol., 43, 182-195, 2004.

Sassen, K.: Indirect climate forcing over the western US from Asian dust storms, Geophy. Res. Lett., 29(10), 1465, doi:10.1029/2001GL014051, 2002.

Satoh, M., Tomita, H., Miura, H., Iga, S., and Nasuno, T.: Development of a global cloud resolving model - a multi-scale structure of tropical convections, J. Earth Simulator, 3, 1-9, 2005.

Shi, J. J., Tao, W.-K., Matsui, T., Hou, A., Lang, S., Peters-Lidard, C., Jackson, G., Cifelli, R., Rutledge, S., and Petersen, W.: Microphysical Properties of the January 20-22 2007 Snow Events over Canada: Comparison with in-situ and Satellite Observations, J. Appl. Meteor. Climatol., submitted, 2009.

Tao, W.-K. and Simpson, J.: The Goddard Cumulus Ensemble Model. Part I: Model description, Terrestrial, Atmospheric and Oceanic Sciences, 4, 19-54, 1993.

Tao, W.-K.: Goddard Cumulus Ensemble (GCE) model: Application for understanding precipitation processes, Cloud Systems, Hurricanes, and the Tropical Rainfall Measuring Mission (TRMM): A Tribute to Dr. Joanne Simpson, Meteor. Monogr., Am. Meteor. Soc., 51, 107-138, 2003.

Tao, W.-K., Simpson, J., Baker, D., Braun, S., Chou, M.-D., Ferrier, B., Johnson, D., Khain, A., Lang, S., Lynn, B., Shie, C.-L., Starr, D., Sui, C.-H., Wang, Y., and Wetzel, P.: Microphysics, radiation and surface processes in the Goddard Cumulus Ensemble (GCE) model, Meteorol. Atmos. Phys., 82, 97-137, 2003.

Tao, W.-K., Johnson, D., Shie, C.-L., and Simpson, J.: Atmospheric energy budget and large-scale precipitation efficiency of con- 
vective systems during TOGA COARE, GATE, SCSMEX and ARM: Cloud-resolving model simulations, J. Atmos. Sci., 61, 2405-2423, 2004.

Tao, W.-K., Smith, E., Adler, R., Haddad, Z., Hou, A., Iguchi, T., Kakar, R., Krishnamurti, T. N., Kummerow, C., Lang, S., Meneghini, R., Nakamura, N., Nakazawa, T., Okamoto, K., Olson, W., Satoh, S., Shige, S., Simpson, J., Takayabu, Y., Tripoli, G., and Yang, S.: Retrieval of latent heating from TRMM measurements, B. Am. Meteorol. Soc., 87, 1555-1572, 2006.

Tao, W.-K., Li, X., Khain, A., Matsui, T., Lang, S., and Simpson, J.: The role of atmospheric aerosol concentration on deep convective precipitation: Cloud-resolving model simulations, J. Geophys. Res., 112, D24S18, doi:10.1029/2007JD008728, 2007.

Tao, W.-K., Chern, J., Atlas, R., Randall, D., Lin, X., Khairoutdinov, M., Li, J.-L., Waliser, D. E., Hou, A., Peters-Lidard, C., Lau, W., and Simpson, J.: Multi-scale modeling system: Development, applications and critical issues, B. Am. Meteorol. Soc., 90, 515-534, available at: http://ams.allenpress.com/perlserv/ ?request=get-toc-aop\&issn=1520-0477, 2009.

Tao, W.-K. and Moncrieff, M.: Multi-scale cloud-system modeling, Rev. Geophys., in press, doi:10.1029/2008RG000276, 2009.

Thompson, A. M., Pickering, K. E., Dickerson, R. R., Ellis, W. G., Jacob, D. J., Scala, J. R., Tao, W.-K., McNamara, D. P. and Simpson, J.: Convective transport over the central United States and its role in the regional CO and Ozone budgets, J. Geophys. Res., 99, 18703-18711, 1994.
Wang, Y., Tao, W.-K., Simpson, J., and Lang, S.: The sensitivity of tropical squall lines (GATE and TOGA COARE) to surface fluxes: 3-D Cloud resolving model simulations, Q. J. Roy. Meteorol. Soc., 129, 987-1007, 2003.

Van den Heever, S., Carrio, G. G., Cotton, W. R., DeMott, P. J., and Prenni, A. J.: Impacts of nucleating aerosol on Florida Storms. Part I: Mesoscale Simulations, J. Atmos. Sci., 63, 1752-1775, 2006.

Zeng, X., Tao, W.-K., Zhang, M., Lang, S., Peters-Lidard, C., Simpson, J., Xie, S., Kumar, S., Geiger, J. V., Shie, C.-L., and Eastman, J. L.: Evaluation of long-term cloud-resolving modeling with observational cloud data, J. Atmos. Sci., 64, 4153-4177, 2007.

Zeng, X., Tao, W.-K., Lang, S., Hou, A., Zhang, M., and Simpson, J.: On the sensitivity of Atmospheric ensemble to cloud microphysics in long-term cloud-resolving model simulations, J. Meteor. Soc. Japan, Special Issue on high-resolution cloud models, 86A, 45-65, 2008.

Zeng, X., Tao, W.-K., Zhang, M.-H., Hou, A. Y., Xie, S., Lang, S., Li, X., O'C Starr, D., and Li, X.: A contribution by ice nuclei to global warming, Q. J. Roy. Meteorol. Soc., in press, doi:10.1002/qj.449, 2009. 